GLOBAL CHILD HEALTH

\title{
Child survival: district hospitals and paediatricians
}

\section{English}

Arch Dis Child 2005;90:974-978. doi: 10.1136/adc.2005.074468

In a previous article in this series, Zulfiquar Bhutta outlined many of the key sociopolitical issues, both national and international, that currently affect the delivery of health care to children in developing countries. 'The clear summary of our situation is that we are failing to provide even basic health care (both preventive and curative) that could reduce child mortality globally by more than half. ${ }^{2}$ Paediatricians, who have perhaps in the past felt they were at the forefront of articulating and promoting a global health agenda, should be challenged by these conclusions. The successful ratification of the United Nations Convention on the Rights of the Child 3 that unequivocally target health was not a finishing line, a goal achieved, but rather a foundation for action. Therefore while researchers might have felt some satisfaction at successes in defining optimum treatment approaches, the pathways to delivering services were, and remain, far from clear. Progress is further complicated by the diverse conditions and obstacles that may be encountered worldwide.

\section{Correspondence to: Dr M English, Kenya Medical Research Institute/ Wellcome Trust Collaborative Programme, PO Box 43640, 00100 GPO, Nairobi, Kenya; Menglish@wtnairobi. mimcom.net}

Accepted 8 April 2005
$\mathrm{S}$ o what can be done? One of the difficulties in discussing global health is the implication that there are global solutions-if only we could purchase a handful of vitamins, micronutrients, and antibiotics for the world's children or invent a new vaccine then all would be well. At the very least such a view ignores the questions of who will deliver these life saving interventions and where, how will such people be trained and continuously supplied (and who is training the trainers), what should they do when a serious problem is encountered, and so on. Delivering health services anywhere in the world is complex, with the most peripheral processes affected by events at each intervening level up to the most central, highest levels of policy and provision. Current health systems also reflect past decisions, policies, and performance locally, nationally, and internationally, contributing to considerable variation in strengths and weaknesses. The result is that solutions must often be local and incremental. They also need to address the entire chain of roles required to deliver health care. Thus while primary care is critical and may ultimately yield the greatest reduction in child mortality, this may be best achieved with the support of an effectively functioning basic community or district hospital. It is these facilities and their role in improving global child health that I will focus on. As any data and insights are derived largely from the Kenyan context, this country is briefly introduced.

\section{KENYA}

In terms of development, Kenya, a country of 30 million people, occupies the middle ground economically in sub-Saharan Africa with a gross national income (GNI) of $\$ 360$ per capita, roughly on a par with Bangladesh, slightly lower than India, and considerably lower than China (GNI \$960). ${ }^{4}$ What does this mean? For $60 \%$ of the population it means survival on an income of $<\$ 2(£ 1.15)$ a day, ${ }^{4}$ with fewer than half of the people having access to safe sanitation or drinking water. ${ }^{5}$ Rural and increasingly urban poverty and inequitable distribution of wealth are therefore among Kenya's major "health" problems, contributing to indicators showing that 1 in 9 live born babies will die before they are 5 years old (with a quarter of these deaths occurring in the neonatal period). Added to these traditional challenges for health systems it is now estimated that 100000 children aged less than 15 are HIV infected, while 300000 children have lost one or both parents to AIDS. ${ }^{5}$

What resources are there to tackle these huge health problems? At present Kenya probably has 20-fold fewer doctors and 4 fold fewer hospital beds than the UK per head of population. ${ }^{4}$ However, it would be incorrect to assume that major investment in new healthcare facilities or personnel alone would transform the health of Kenya's children. At present, in many areas one third of childhood deaths occur at home without any contact with formal healthcare services at all, another third occur at home having received primary care only within 48 hours of death, leaving the remaining third dying in hospital. ${ }^{6}$ These statistics underline the need for effective healthcare interventions delivered at the household, community, and primary care levels. Care in small hospitals represents just the apex of the pyramid of primary care.

\section{SMALL HOSPITALS: THEIR POTENTIAL TO ENHANCE CHILD SURVIVAL}

District hospitals, often with 80-200 beds, may, by concentrating staff and resources, be able to offer aspects of life saving care that cannot be delivered efficiently at primary care level (examples are provided in table 1 ). If well run, it has been estimated that they may reduce child mortality in the area they serve by $44 \%$ compared with the absence of any hospital. ${ }^{7}$ However, a more realistic scenario than comparing the presence and absence of hospital care would be to consider the possible impact of improving a poorly functioning facility. Very crude estimates 
Table 1 Functions of a district or community hospital that may compliment primary care and improve length or quality of life for children

\begin{tabular}{|c|c|}
\hline Trauma & Basic medical and surgical management \\
\hline $\begin{array}{l}\text { Acute } \\
\text { surgery }\end{array}$ & $\begin{array}{l}\text { Appendicectomy } \\
\text { Reduction of intussusception } \\
\text { Skin grafting for burns }\end{array}$ \\
\hline $\begin{array}{l}\text { Perinatal } \\
\text { care }\end{array}$ & $\begin{array}{l}\text { Pregnancy monitoring and interventional delivery } \\
\text { Advanced newborn resuscitation, } \\
\text { Supportive care of infants with: } \\
\text { Asphyxia } \\
\text { Very low birth weight } \\
\text { Prematurity }\end{array}$ \\
\hline $\begin{array}{l}\text { Acute } \\
\text { medical } \\
\text { care }\end{array}$ & $\begin{array}{l}\text { Ongoing monitoring and clinical review } \\
\text { Management of severe disease, in particular: } \\
\text { Complex or prolonged convulsions } \\
\text { Blood transfusion } \\
\text { Parenteral fluid therapy for shock or severe dehydration } \\
\text { Continuous oxygen therapy for very severe respiratory } \\
\text { distress } \\
\text { Supportive care for a child in coma }\end{array}$ \\
\hline $\begin{array}{l}\text { Chronic } \\
\text { medical } \\
\text { care }\end{array}$ & $\begin{array}{l}\text { Sickle cell disease } \\
\text { Epilepsy } \\
\text { Diabetes } \\
\text { HIV }\end{array}$ \\
\hline
\end{tabular}

suggest that lowering case fatality rates and thus inpatient mortality generally, or improving referral, or both at the district hospital level might reduce child mortality by 3-30\% (fig 1). Although actual case-mix and resources would be major influences on realising this potential, impacts may be comparable to or better than those of new vaccines..$^{8-10}$ Therefore, while hospital care is not an alternative to primary care, its complimentary functions should not be ignored. For example, insecticide treated bednets might reduce episodes of severe malaria in children by $50 \%,{ }^{11}$ an impressive impact, but still one that would leave tens of thousands of children annually requiring hospital treatment for severe malaria in Kenya.

I have emphasised two factors likely to be critical determinants of a hospital's impact (fig 1): the ability to

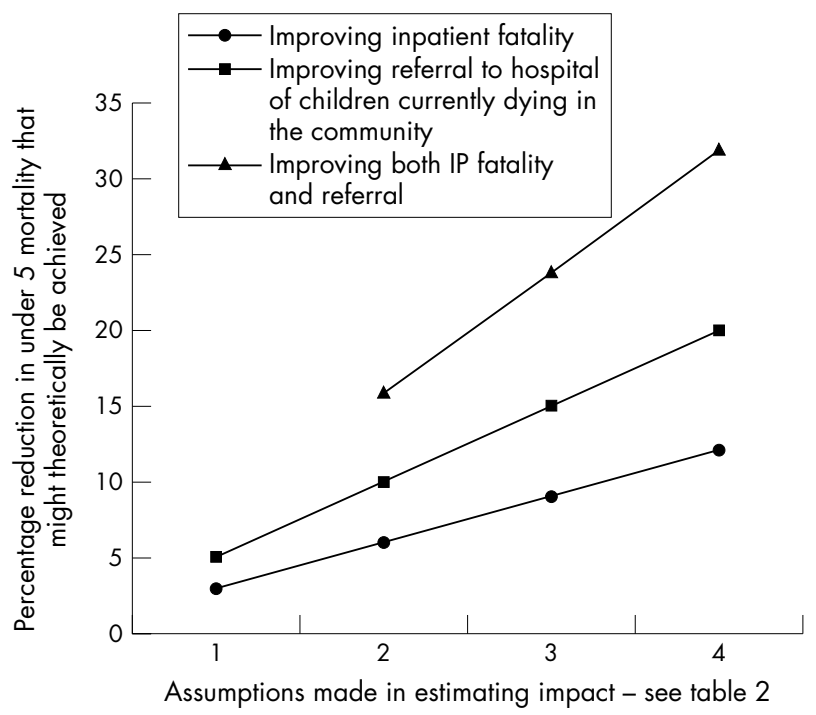

Figure 1 Potential impact on under 5 mortality of improving either district hospital inpatient fatality rates, or the success of referral to hospital, or both, measured at the community level. deliver effective care, and appropriate referral. Optimising treatment seems an achievable goal as only a handful of illnesses (malaria, pneumonia, diarrhoea/dehydration, meningitis, malnutrition, HIV/AIDS, severe neonatal infection or birth asphyxia, prematurity, or very low birth weight ${ }^{*}$ ) account for $80 \%$ or more of admissions and hospital deaths. However, survey work conducted internationally ${ }^{12}$ and in 14 Kenyan hospitals in 2002 has identified some of the problems and difficulties in delivering care. ${ }^{13}{ }^{14}$ (Key findings are summarised in table 3.) Notable is the fact that children in small hospitals are frequently very severely ill, with 1 in 13 children admitted dying in Kenya (range 1 in 7 to 1 in 20), while at least 1 in 20 hospital deliveries result in either a stillbirth or a very early neonatal death. Care for such children is most often given by clinical staff with a three year diploma in medicine and/or nurses, and only rarely provided or supervised by a paediatrician.

A complete discussion of the barriers to referral and access to hospital care in developing countries is not possible here. However, key issues include distance to facilities, lack of money, lack of transport, local perceptions of disease causation (with preference for traditional forms of treatment for some disorders), and lack of faith in the quality and effectiveness of services. ${ }^{15}{ }^{16}$ Of these the last is conceivably the most subject to local control, while the others reflect more strongly system-wide attributes. In particular financial barriers are exacerbated by policies of levying charges for hospital care, costs that may consume a large fraction of entire household monthly incomes. ${ }^{17}$ Despite emerging consensus that those most disadvantaged by these policies are the poor, they are still promoted by global financial institutions (such as the International Monetary Fund) as means to support government health care. ${ }^{18}$

One might pessimistically conclude from this brief overview that Kenya and countries like it should cut their losses, concentrate on primary care, and worry about hospitals later. This policy of despair is, however, a mistake, representing a superficial solution to a series of complex problems. In this sense the arena of health is almost a microcosm of the much wider problems of development.

\section{SMALL HOSPITALS THAT IMPROVE CHILD HEALTH: THE CHALLENGES}

If our concern is maximising child survival, then a rational approach would be to pose the question of how best hospital services can help achieve this goal within a limited, relatively fixed resource boundary. Such thinking underlies the idea of concentrating on basic packages of services ${ }^{19}$-in one sense explicit rationing. Targeting those common diseases resulting in so much morbidity and mortality makes intuitive sense. One practical difficulty, however, with such a process of prioritisation is the need for accurate information to guide resource distribution. How much of which diseases are where? What are the most cost effective interventions? These are just some of the questions that need to be answered to prioritise service delivery. Such a rational approach also focuses primarily on efficiency. This aim can conflict with concern over equity, itself variously defined. Thus, should a fixed array of services be provided equally geographically? Should equality in health status be the goal? Or are policy makers correct to concentrate on the greatest health impact given the available resources (efficiency)? Different choices have different implications for cost effectiveness, access to care, and the health status of vulnerable groups. While there are no easy solutions, two points stand out. First, is the

* As a result of an effective national immunisation programme, measles is not currently a major cause of infant or child mortality in Kenya. 
Table 2 Potential impact on under 5 mortality of improving either district hospital inpatient fatality rates or the success of referral to hospital or both, measured at the community level

\begin{tabular}{|c|c|}
\hline Assumptions & Effect size used to estimate reduction in under 5 mortality. \\
\hline \multicolumn{2}{|c|}{ Improving impatient fatality } \\
\hline 1 & $30 \%$ of all under 5 deaths occur in hospital but IP fatality is reduced to $90 \%$ of baseline \\
\hline 2 & $30 \%$ of all under 5 deaths occur in hospital but IP fatality is reduced to $80 \%$ of baseline \\
\hline 3 & $30 \%$ of all under 5 deaths occur in hospital but IP fatality is reduced to $70 \%$ of baseline \\
\hline 4 & $30 \%$ of all under 5 deaths occur in hospital but IP fatality is reduced to $60 \%$ of baseline \\
\hline \multicolumn{2}{|c|}{ Improving referral to hospital of children currently dying in the community } \\
\hline & $\begin{array}{l}10 \% \text { of the } 70 \% \text { of children previously dying outside hospital are instead successfully referred. IP fatality in this new group is very } \\
\text { conservatively estimated to be as high as 30\% (see note } 2 \text { below) }\end{array}$ \\
\hline 2 & $\begin{array}{l}20 \% \text { of the } 70 \% \text { of children previously dying outside hospital are instead successfully referred. IP fatality as above is very conservatively } \\
\text { estimated at } 30 \% \text { in this new group }\end{array}$ \\
\hline 3 & $\begin{array}{l}30 \% \text { of the } 70 \% \text { of children previously dying outside hospital are instead successfully referred. IP fatality as above is very conservatively } \\
\text { estimated at } 30 \% \text { in this new group }\end{array}$ \\
\hline 4 & $\begin{array}{l}40 \% \text { of the } 70 \% \text { of children previously dying outside hospital are instead successfully referred. IP fatality as above is very conservatively } \\
\text { estimated at } 30 \% \text { in this new group }\end{array}$ \\
\hline \multicolumn{2}{|c|}{ Improving both IP fatality and referral } \\
\hline 2 & Combined effect of both assumptions for IP fatality and referral labelled 2 \\
\hline & Combined effect of both assumptions for IP fatality and referral labelled 3 \\
\hline 4 & Combined effect of both assumptions for IP fatality and referral labelled 4 \\
\hline \multicolumn{2}{|l|}{ Notes } \\
\hline \multicolumn{2}{|c|}{$\begin{array}{l}\text { 1. There are likely to be major differences in the degree to which disease specific case fatality rates can be reduced, thus a hospital's case-mix will be a } \\
\text { considerable influence on the potential for reducing overall inpatient mortality. } \\
\text { 2. It is possible that children not currently referred differ from those easily referred-perhaps they are sicker (referral is not deemed worthwhile), or are in the } \\
\text { terminal stages of chronic illness, or live much further away with the prospect that they will arrive in hospital with less chance of being saved. } \\
\text { 3. An increase in the number of referrals may overload an already busy hospital, resulting in a lower quality of care and a lower than expected impact. }\end{array}$} \\
\hline
\end{tabular}

critical role of accurate and accessible health information on a geographically and administratively relevant scale. Second, the need to empower the people affected by health policy decisions to be informed and involved in decision making, most obviously through some form of representative democracy. ${ }^{20}$

If we accept for the present that effective care for children with the most common, serious diseases is at least a reasonable starting point for hospitals, then how should this be achieved? A standardised, minimum approach to clinical management-in other words establishing guidelines for care that reflect best practice given the available resources-seems a sensible first step. Such initiatives are hardly new, with examples in some developing countries spanning many years (for example, Papua New Guinea), and are encompassed in a generic, global strategy for developing countries promoted by WHO and UNICEF as part of Integrated Management of Childhood Illness (IMCI). ${ }^{21}$ However, although seemingly obvious, even this basic step has yet to be taken in many developing (and developed) country settings.
Defining standard approaches to care will affect practice if health workers are aware of and use any guidelines produced and are equipped with the appropriate resources. Again while obvious, how to achieve this is proving far from straightforward, even in wealthy nations. Although clearly dissemination and training are the starting point, they are rarely, alone, adequate, ${ }^{22}$ questioning the impact of the large sums spent by organisations that measure their effectiveness solely on the basis of how many people have attended their courses. If training and guidelines are to have an impact they must be provided within a context that enhances and promotes their use-within a health system that provides reminders, supportive supervision, feedback ${ }^{23}$ and, perhaps, more formal quality assurance. ${ }^{24}$ Even these approaches, primarily focused directly at the provider of care, are alone insufficient. Thus adequate resource allocation, effective regulation of healthcare delivery, clinical governance, and promoting a culture of trust and personal accountability ${ }^{25}$ must be developed system-wide. The parallels with current health system goals

Table 3 The performance of hospitals in delivering paediatric care in developing countries: a summary of some recent findings

\begin{tabular}{ll}
\hline Reference & Findings \\
\hline Nolan et $a l^{12}$ & $\begin{array}{l}\text { No or ineffective triage for sick children arriving at hospital, resulting in potentially dangerous delays in initiating treatment } \\
\text { Absence of basic, essential supplies for handling emergencies in "walk-in" areas of the hospital } \\
\text { Indications of some inadequacy in care in } 76 \% \text { of admitted children } \\
\text { Inadequate knowledge base of many health professionals for even common, serious childhood disorders }\end{array}$ \\
Absence of paediatricians and doctors, limited numbers of nurses \\
Basic resources often missing or inadequate, for example: \\
Oxygen \\
Blood for transfusion \\
Phototherapy equipment \\
Inhaled therapy for asthma \\
Feeds for malnourished children or sick newborn infants \\
Lack of access to or knowledge about modern case management approaches \\
Basic laboratory investigations (e.g. examination of CSF) unavailable, of poor quality, or not used \\
Serious dose errors for even commonly used drugs \\
Inadequate/inappropriate use of intravenous fluids
\end{tabular}


in wealthy nations are obvious. Although the technical complexity of care offered may be very different, the tools required for effective implementation of best practice care are much more closely related.

What factors hinder these apparently logical developments? The list of potential barriers to improving clinical care of children is long and I will highlight only a few. The most obvious and frequently cited system-wide difficulty is lack of money. However, often this is all that is said, the tacit implication being that large increases in health budgets will by themselves improve things. Clearly this is not necessarily the case unless the money is targeted, at least partly, to developing and supporting delivery and monitoring systems, including adequate information systems. Difficulties achieving this may reflect the forces at work in deciding how funds are used. Thus perhaps for the local political establishment and for donors the high profile purchase of life-saving drugs is considerably more attractive than tackling complex issues such as human resources and the organisation of care. This can be exacerbated by the often short term agendas of politicians and donors with the latter potentially able to undermine local autonomy, distort priorities, and slow as well as speed up the pace of policy development and implementation. ${ }^{26}$ For example, it is quite possible that soon more hospitals in Kenya will be able to measure a CD4 count than perform basic microscopy and culture of CSF for meningitis.

At a national and local level a country's health workers are critical to any change in healthcare delivery. The severe shortage of personnel at all levels in developing country health systems has recently become a topic of increasing attention and concern. ${ }^{27}$ Put quite simply change will not be possible until there are adequate pairs of hands to provide even basic care. Addressing this problem will require long term investment in training and expansion of budgets for personnel, the latter an anathema to the global financial institutions and thus to local Ministries of Finance. However, it also demands much improved human resource planning, workforce regulation (including transparent procedures for discipline and promotion that are consistently and fairly applied), and the dismantling of entrenched systems of patronage. These practical measures may be important at a wider level in improving the motivation of health workers and fostering their trust and confidence in a just health system. ${ }^{25}$ More creative solutions may also be needed. Thus flexibility in clinical roles, for example devolving some traditionally medical tasks to clinical assistants or nurses or wider use of healthcare assistants, might help improve access to or quality of services. Motivation will also depend on adequate conditions within which to deliver high quality of care, and basic minimum standards demand continuous availability of a basic set of resources. For the small proportion of children admitted with complex diseases beyond the capacity of these resources, health workers must not be made to feel they personally have failed. Maintaining morale when children with "treatable" conditions, such as respiratory failure complicating bronchiolitis or Burkitt's lymphoma, die despite effective basic care is difficult but vital. In many moderately sized rural hospitals at least one child dies every day. Learning in a constructive way how care might be improved while providing support for those frustrated by feelings that children have been denied adequate care is a delicate but vital task. ${ }^{28}$

\section{PAEDIATRICIANS}

It is clear that improving care in small hospitals may require both additional financial support and the willingness and ability within a country to work towards defined goals. What role is there for paediatricians as advocates and actors for improving child survival as part of this process? Although discussing issues at a more global level, Zulfiquar Bhutta identified a critical requirement, leadership. ${ }^{1}$ In most developing countries approximately half of the population is aged less than 15 years. Half of the population are thus politically silent and to some, therefore, irrelevant. Those with the greatest interest in a child's future, their parents or guardians, must be encouraged and helped to consider their present and future needs. Although the future may seem of little concern when there are daily difficulties in providing adequate food, shelter, and education, families, and perhaps particularly women, must themselves be empowered as advocates. Leadership is therefore not invested only in a few individuals but is required at all levels from the household upwards, albeit with somewhat different demands, and paediatricians must lend their weight to these efforts.

While paediatricians appear naturally to occupy the leadership ground within the formal healthcare system, they should be encouraged to reflect on their real ability to undertake this role. Within the government health systems in many developing countries, paediatricians do not provide primary care, and even at the hospital level are often only found in large urban centres. As highly trained professionals, paediatricians understandably desire to practice the advanced skills they have learned and, in common with comparable professional groups, are frequently and understandably pursuing an income commensurate with their professional and social status. It is therefore naive to expect them to consider working for poor government salaries in often remote rural locations with few social amenities. This is a situation likely to persist for many years in Kenya where only 10 paediatricians a year graduate (although individuals who do offer this service deserve great respect and should be actively supported). It is obvious therefore that the interests of urban paediatricians and child health more generally can easily conflict and leaders must strive for an appropriate balance (consider the government purchase of neonatal ventilators for a national hospital).

Thus, promoting the development of paediatrics as a skilled, clinical discipline with appropriate sub-specialisation may help satisfy the aspirational component of development, prevent stagnation, allow developing country paediatricians to interact on an equal footing with colleagues internationally and, probably most importantly, help retain motivated, enthusiastic practitioners and teachers. International support for development in this area remains important. However, if this is the only area in which paediatrics in developing countries flourishes, it risks becoming irrelevant to the health of most children. Where paediatrics is primarily an urban, technical profession, there may therefore be a need now to foster actively alliances with alternative professional or civil groups able to share the role of advocating more broadly for child health.

Priority should also be given to developing paediatricians who take on a responsibility for the delivery of basic but effective systems of care. To achieve this we (internationally) need to counter pervasive views that such roles are somehow academically less worthy. Those who lead these areas should have the same status as sub-specialists in highly technical disciplines and be treated equally financially. International paediatric bodies, including the Royal College, can do much to help by recognising such groups and supporting initiatives aimed at improving the quality of health systems at all levels in developing countries. As the overwhelming majority of care for sick children is provided by people without specialist paediatric knowledge, the task of developing innovative solutions to promote child health is one of the real challenges facing this class of paediatricians. Working with local, facility 
based advocates may be helpful, but currently support for this type of outreach is almost non-existent. Although developments in information technology should, in theory, make communicating and supporting scattered and often somewhat isolated advocates much easier, in practice this remains an empty promise in most African settings at least. Even large government teaching and provincial hospitals in many African countries have no institutional access to email or the internet.

The implication of many of the views I have presented is, I hope, obvious. Improving child survival in many developing countries will depend on the actions of the major global economies and the actions of institutions, communities, and individuals nationally. The former through pursuing the health related Millennium Development Goals ${ }^{29}$ and in creating a fairer global economy. ${ }^{30}$ Without local engagement, however, it is likely that little will be achieved. Sadly in many countries institutions important to child health (such as universities, clinical training schools, and professional or civil associations) are weak, being very poorly resourced in terms of manpower and facilities. Building credible, local institutions that can unlock the potential of expert, influential, local personnel is a key task that rarely attracts adequate support. Yet without such local champions, progress towards child survival risks being undermined by competing priorities or sidelined as another "donor priority". Such institutions are also a fundamental step in the development of a truly independent, national capacity to set priorities for and deliver high quality child health care, surely the ultimate aim.

Therefore, just as developing country paediatricians may have to be innovative to support the children they are in one sense answerable to, the same is true of paediatricians internationally. We must be committed for the long term, aim to build national capacities, nurturing strengths as they emerge, even if they are from non-traditional quarters, be actively engaged in efforts that help countries keep their most valuable human resources, and be in the forefront of efforts to use global resources responsibly in the interests of all children.

\section{ACKNOWLEDGEMENTS}

I gratefully acknowledge the many informal discussions I have had with colleagues in Kenya and elsewhere that contributed indirectly to this piece, and in particular the comments of Trevor Duke and Bob Snow.

Funding: Mike English is supported by a Wellcome Trust Fellowship (\#050563) for work in Kenya

Competing interests: none declared

All views expressed are personal and do not reflect any official viewpoint of the Kenya Medical Research Institute or The Wellcome Trust (UK)

\section{REFERENCES}

1 Bhutta Z. Beyond Bellagio: addressing the challenge of sustainable child health in developing countries. Arch Dis Child 2004;89:483-7.

2 The Bellagio Study Group for Child Survival. Knowledge into action for child survival. Lancet 2003;362:323-7.

3 Office of the High Commissioner for Human Rights. Convention on the rights of the child. United Nations, 1989. www.unhchr.ch/html/menu2/6/crc/ treaties/crc.htm (accessed 12 January 2005).

4 World Bank. http://web.worldbank.org/5 (accessed 12 January 2005).

5 UNICEF, Kenya country profile, 2005. http://www.unicef.org/ infobycountry/kenya.html (accessed 8th January 2005).

6 Snow R, Schellenburg J, Forster $D$, et al. Factors influencing admission to hospital during terminal childhood illnesses in Kenya. Int I Epidemiol 1994;23:1013-19.

7 Snow R, Mungala V, Forster D, et al. The role of the district hospital in child survival at the Kenyan Coast. Afr J Health Sci 1994;1:1 1-15.

8 Jones G, Steketee R, Black R, et al. How many child deaths can we prevent this year? Lancet 2003;362:65-71.

9 Mulholland K, Hilton S, Adegbola R, et al. Randomised trial of Haemophilus influenzae type- $b$ tetanus protein conjugate vaccine for prevention of pneumonia and meningitis in Gambian infants. Lancet 1997;349:1191-7.

10 Klugman K, Madhi S, Huebner R, et al. Trial of a 9-valent pneumococcal conjugate vaccine in children with and those without HIV infection. N Engl J Med 2003;349:1341-8.

11 Nevill C, Some E, Mung'ala V, et al. Insecticide-treated bednets reduce mortality and severe morbidity from malaria among children on the Kenyan coast. Trop Med Int Health 1996;1:139-46.

12 Nolan T, Angos P, Cunha A, et al. Quality of hospital care for seriously ill children in less-developed countries. Lancet 2000;357:106-10.

13 English M, Esamai F, Were F, et al. Assessment of inpatient paediatric care in first referral level hospitals in 13 districts in Kenya. Lancet 2004;363:1948-63.

14 English M, Esamai F, Were F, et al. Delivery of paediatric care at the first referral level in Kenya. Lancet 2004;324:1622-9.

15 Peterson S, Nsugwa-Sabiti J, Were W, et al. Coping with paediatric referral-Ugandan parents' experience. Lancet 2004;363:1955-6.

16 Nordberg E, Holmberg S, Kiugu S. Exploring the interface between first and second level of care: referrals in rural Africa. Trop Med Int Health 1996; 1:107-11.

17 Xu, K, Evans D, Kawabata K, et al. Household catastrophic health expenditure: a multicountry analysis. Lancet 2003;362:111-17.

18 Arhin-Tenkorang D. Mobilizing resources for health: the case for user fees revisited. Washington: Commission for Macroeconomics in Health, 2000.

19 Bobadilla JL. Searching for essential health services in low and middle income countries. Washington: World Bank, 1998.

20 Sen A. Development as freedom. New York: Anchor Books, 2000.

21 World Health Organisation. Management of the child with a serious infection or severe malnutrition. Geneva: World Health Organisation, 2000.

22 Grol R, Grimshaw J. From best evidence to best practice: effective implementation of change in patients' care. Lancet 2003;362:1225-30.

23 Grimshaw J, Thomas R, Maclennan G, et al. Effectiveness and efficiency of guideline dissemination and implementation strategies. Health Technol Assess 2004;8(6):iii-iv, 1-72.

24 Massoud R, Askov K, Reinke J, et al. A modern paradigm for improving healthcare quality. Bethesda: Quality Assurance Project, 2001.

25 Blaauw D, Gilson L, Penn-Kekana L, et al. Organisational relationships and the 'software' of health sector reform. Disease Control Priorities Project Background Paper. Washington, DC, 2003.

26 Brugha R, Donoghue $M$, Starling $M$, et al. The Global Fund: managing great expectations. Lancet 2004;364:95-100.

27 Chen L, Evans T, Anand S, et al. Human resources for health: overcoming the crisis. Lancet 2004;364:1984-90.

28 Duke T, Tamburlini G. Improving the quality of paediatric care in peripheral hospitals in developing countries. Arch Dis Child 2003;88:563-5.

29 United Nations Development Programme. Millenium Development Goals, 2003. http://www.undp.org/mdg/ (accessed 12 January 2005).

30 Sanders D. Macroeconomic reform is necessary to progress in the MDGs. Bull World Health Organ 2004;82:952. 